\title{
Herpetological Journal 2020 and beyond - Issue 30(1)
}

$D^{\prime}$ uring the past decade we have seen significant advancements in our understanding of herpetological diversity, ecology, behaviour and conservation. Depressingly, many amphibian and reptile species, however, have become extinct or undergone large declines over this period. Of all vertebrates, amphibians are one of-if not the-organismal group of most conservation concern, with $41 \%$ of species threatened with extinction (IUCN, 2019) and some estimates suggest that an additional ca. 1,000 of the IUCN's Data Deficient species are threatened with extinction (González-delPliego et al., 2019).

Unfortunately, it is likely that these declines will increase over the next decade. The Herpetological Journal has played a pivotal role in building our understanding of all elements of herpetological biology, consequently informing appropriate conservation actions to be taken.

The current issue of The Herpetological Journal epitomises the range of studies in reptile and amphibian biology and spans the many topics that the journal covers. This issue has articles discussing taxonomic and phylogenetic relationships of snakes (Eskandarzadeh et al., 2020), how captivity affects skin colour in frogs (Passos et al., 2020), population changes in long term datasets of lizards (Meek, 2020), amphibian distribution and endemism in South America (Cabral et al., 2020; Ribeiro Morais et al., 2020), and a global review of monoand bispecific genera of amphibians (Amori et al., 2020).

The Herpetological Journal welcomes manuscripts about any aspect of herpetology, that are of high scientific standard and of general interest, including taxonomic papers. Previously we have been accepting the following manuscript types: full length papers, short notes, reviews, mini-reviews and opinion/perspective pieces. Moving forward we will be maintaining these formats but will be adding policy-based manuscripts, given the importance of setting correct policy-based procedures for conservation.

As well as scientific advancements, the past decade has increasingly seen authors choosing to publish using Open Access. At the British Herpetological Society, we strongly encourage Open Access to allow scientific knowledge to be freely available to the public and as such, to our knowledge, we are the cheapest Open Access journal for herpetology, globally. Open Access is available free to members (membership rates from as little as $£ 18$ pa - can join during submission process) or $f 97$ for nonmembers. We strongly encourage authors to use the Open Access option as a way of attracting attention and therefore impact (citations) for your articles.
Here is to another 10 years of herpetological advancements!

\section{REFERENCES}

Amori, G., Bologna, M. A. \& Luiselli, L. (2020). A review of monoand bispecific genera of Amphibians worldwide. Herpetological Journal 30(1), 47-51. doi: https://doi. org/10.33256/hj30.1.4751.

Cabral, H., Casagranda, M. D., Brusquetti, F., Netto, F., Ferreira, V. \& Lavilla, E. (2020). Multiscale endemism analysis for amphibians of Paraguay. Herpetological Journal 30(1), 3546. doi: https://doi.org/10.33256/hj30.1.3546.

Eskandarzadeh, N., Rastegar-Pouyani, N., Rastegar-Pouyani, E., Todehdehghan, F., Rajabizadeh, M., Zarrintab, M., Rhadi, F. A. \& Kami, H. G. (2020). Revised classification of the genus Eryx Daudin, 1803 (Serpentes: Erycidae) in Iran and neighbouring areas, based on mtDNA sequences and morphological data. Herpetological Journal 30(1), 2-12. doi: https://doi.org/10.33256/hj30.1.212.

González-del-Pliego, P., Freckleton, R. P., Edwards, D. P., Koo, M. S., Scheffers, B. R., Pyron, R. A. \& Jetz, W. (2019). Phylogenetic and trait-based prediction of extinction risk for data-deficient amphibians. Current Biology 29, 15571563. doi: 10.1016/j.cub.2019.04.005.

IUCN (2019) https://www.iucnredlist.org/. Available at: https:// www.iucnredlist.org/.

Meek, R. (2020). Temporal trends in Podarcis muralis and Lacerta bilineata populations in a fragmented landscape in western France: Results from a 14 year time series. Herpetological Journal 30(1), 20-26. doi: https://doi.org/10.33256/ hj30.1.2026.

Passos, L. F., Garcia, G. \& Young, R. (2020). How does captivity affect skin colour reflectance of golden mantella frogs? Herpetological Journal 30(1), 13-19. doi: https://doi. org/10.33256/hj30.1.1319.

Ribeiro Morais, A., Lucas Andreani, T., Alves, R., Emília dos Santos, C., Rodrigues Rezende, W. \& Lemes, P. (2020). Anurans species in Brazil's protected areas network. Herpetological Journal 30(1), 27-34. doi: https://doi.org/10.33256/ hj30.1.2734.

Simon Maddock

Faculty of Science and Engineering, Univer-

sity of Wolverhampton, WV1 1LY, UK

s.maddock@wlv.ac.uk

Scientific Editor 